\title{
- MERCAdo de INFORMAÇÃo NO SETOR TURÍSTICO BRASILEIRO
}

\author{
Lidia Eugenia Cavalcante \\ Edna Leite Dias
}

\section{Resumo}

Aponta que o setor de serviços, especialmente a área do turismo, representa um dos principais fatores de crescimento econômico do País nos últimos anos. Muitos são os investimentos públicos e privados destinados ao turismo no Brasil, o que reflete significativamente na geração de emprego e renda. Destaca que a competitividade e a qualidade da oferta de produtos e serviços turísticos passam necessariamente pelo fator informação, evidenciando como uma das principais exigências dos consumidores desse mercado, todavia, ainda, negligenciado. Para o profissional da informação, o turismo apresenta-se como um mercado emergente e não-convencional gerador de múltiplas possibilidades de atuação.

\section{Palavras Chave}

Informação e turismo; Mercado de Informação; Profissional da Informação; Turismo; Crescimento Econômico.

\section{INTRODUÇÃO}

O turismo é um fenômeno dos mais característicos do nosso tempo. Trata-se de um movimento que cresce cada vez mais no mundo e ocupa lugar de interesse em todos os países. As nações deixam de ficar indiferentes a este fenômeno, pois pessoas se locomovem de um lugar para outro e esses deslocamentos afetam economicamente as regiões, direta ou indiretamente, gerando riquezas. Não se trata apenas de 
uma indústria de alta importância econômica, é também um fator produtor de efeitos nas áreas cultural, social e política.

A indústria turística, sob o aspecto econômico, dinamiza a economia incentivando a produção de bens, o setor de serviços e o comércio global, nacional, regional e local, promovendo a criação de novos postos de trabalho. Percebe-se, ainda, que a questão do turismo encontra-se ligada economicamente a outras atividades contribuindo para o desenvolvimento das regiões de forma bem abrangente.

Nos países de economia em franco desenvolvimento, o número de pessoas que usufrui, pelo menos uma vez ao ano de férias e faz turismo, cresce acentuadamente. A viagem turística, dentro ou fora do país, é cada vez mais considerada no orçamento familiar, tornando-se gradualmente um artigo de usufruto comum nas sociedades de consumo. A promoção econômico-social, as progressivas exigências da sociedade de competição e a oferta sempre mais aliciante no campo do turismo combinamse para o contínuo crescimento deste fenômeno.

O turismo não pode ser encarado apenas como mais uma das atividades econômicas e culturais da sociedade moderna, nem tão pouco como uma forma de lazer de privilegiados. Deve, portanto, ser entendido e fomentado como um instrumento de progresso, tanto econômico quanto social, pois seu sucesso refletirá especialmente na geração de emprego e renda e na arrecadação de impostos.

Contudo, avaliar a questão turística para o desenvolvimento econômico e social pressupõe, fundamentalmente, uma análise crítica sobre as vantagens e desvantagens desse fenômeno e os impactos causados nas regiões e comunidades com a sua promoção.

Nos últimos anos, o turismo tem atingido grandes proporções. Passou a ser visto como um campo em franco desenvolvimento nas regiões brasileiras, levando vários segmentos a encará-lo como forma preponderante de investimento e lucro.

Todavia, é necessário destacar a importância do fator informação, indispensável ao crescimento das regiões brasileiras enquanto pólo de desenvolvimento turísti$\mathrm{co}$, o que representa uma das principais reivindicações dos consumidores desse mercado.

\section{TURISMO: CRESCIMENTO ECO- NÔMICO E SOCIAL}

O turismo é uma atividade marcante na sociedade atual ocupando lugar de destaque nas relações internacionais. De acordo com Castelli (1986), "O turismo tornouse um fenômeno tão marcante no século XX que segundo previsões feitas por especialistas e organismos de turismo, ele se constituirá na primeira atividade mundial em termos de receita e no maior empregador de mão-de-obra, por volta do ano 2000." Com efeito, torna-se na era moderna um dos principais geradores de riquezas, a nível econômico, social e cultural.

No Nordeste brasileiro, o turismo vem se consolidando como atividade de elevada importância, repercutindo tanto na geração de renda e emprego, como também no aumento das arrecadações tributárias para os estados e municípios. Mesmo levando em consideração o potencial turístico da região, percebe-se a necessidade de um planejamento estratégico mais dinâmico, consolidando de forma mais eficiente e eficaz esse grande potencial gerador de riquezas. 
A década de 90 é um marco para o setor turístico brasileiro. No Ceará, segundo a Secretaria de Turismo do Estado, no ano de 1995 a taxa de ocupação hoteleira registrou, em média, índices de $70 \%$ na capital, considerando também os meses de baixa estação. De acordo com a CODITUR - Companhia de Desenvolvimento Industrial e Turístico do Ceará, em 1991, Fortaleza contava com 8.090 leitos. Atualmente, a cidade oferece cerca de 22.000 leitos entre hotéis, flats, pousadas e apartamentos de temporada, 126 agências de viagem e 21 locadoras de veículos. Paralelamente a esses dados, verifica-se um aumento significativo no parque de diversões turísticas como: praias, cidades turísticas, parques aquáticos, parques ecológicos, bares, restaurantes, casas noturnas, destacando-se ainda, no artesanato, na moda, na culinária, e no humor, este último representando uma das principais atrações da vida noturna da cidade de Fortaleza.

Em termos de produto turístico, o Ceará é especialmente privilegiado por suas belezas naturais: praias, dunas, clima, serra e sertões. Assim, o turismo surge como um fator de aproveitamento e desenvolvimento desses recursos, capaz de transformá-los em importante gerador de fonte de riquezas para o Estado.

O Governo do Estado, atualmente, busca uma melhor redefinição do setor turístico no Ceará, através da criação de macrorregiões, observando os aspectos físicos, ambientais e sócio-econômicos de cada região envolvida, especialmente do litoral; maiores investimentos na área de marketing e propaganda turística e no setor comercial e industrial com o incentivo à implantação de indústrias de pequeno, médio e grande porte. Tais medidas visam incrementar o turismo nos municípios e descentralizar a concentração do mercado tu- rístico em Fortaleza, aumentando a arrecadação e geração de riquezas no interior.

O fator desenvolvimento turístico passa, necessariamente, pela adoção de estratégias de crescimento demográfico e social sustentável, de mercado e capacitação de recursos humanos para o setor, pois, além das belezas naturais, o turismo pressupõe pessoal qualificado, treinado e especializado para o atendimento do turista que está sempre esperando ser bem tratado e atendido em todas as suas necessidades e expectativas.

O turismo é um setor que não funciona e não cresce isoladamente. Há uma forte relação com os demais setores da economia da região. $O$ investimento em infraestrutura, transporte, segurança, hospitais, restaurantes, hotéis e bancos, para citar alguns, não pode ser negligenciado, podendo afetar negativamente os objetivos de crescimento do setor.

A oferta turística deve estar intrinsecamente ligada à sua demanda e a todo um sistema que funciona conjuntamente, no qual o investimento deve ser primordial: estrutura, serviços, instalações, equipamentos, tecnologia, comunicação e propaganda, atrativos, lazer e a própria manutenção do sistema.

As políticas de desenvolvimento do turismo na região Nordeste e no País como um todo devem estar dentro dos parâmetros internacionais e de acordo com as novas exigências do cliente e da demanda por produtos turísticos. A projeção mundial do turismo precisa ser um dos principais pontos estratégicos dentro da nova política de crescimento econômico que ora se projeta. Não é possível mais falar em desenvolvimento local ou apenas nacional. Com a globalização da economia, o território turístico passa a ser mundial. Tornar-se com- 
petitivo é uma das principais metas de mercado.

Um dos objetivos da política de desenvolvimento do setor é a geração de emprego e renda. A criação de empregos diretos e indiretos, gerados através do crescimento turístico visa amenizar uma das principais ameaças que preocupam o governo atualmente: o desemprego e a situação do mercado de trabalho. Nessa perspectiva, empresas privadas e governo devem ter como meta o treinamento e a qualidade das populações locais para capacitação de mão-de-obra para o setor, o que ainda é muito deficiente.

A organização da iniciativa privada constitui-se importante mecanismo de fortalecimento das políticas de crescimento econômico do turismo. Porém, grande parcela dessa responsabilidade ainda se encontra nas mãos do setor público, especialmente no que se refere a infra-estrutura básica, segurança, transportes, malha rodoviária, entre outros, tornando o seu papel imprescindível no fomento ao crescimento da economia.

Mesmo com o crescimento observado no setor turístico nos últimos anos, é importante ressaltar que a situação da população brasileira como um todo, particularmente na região Nordeste onde se observa maior crescimento do pólo turístico, ainda é muito precária quando se trata de políticas voltadas para as áreas de investimentos públicos como saúde, educação, saneamento básico, segurança e emprego, o que aumenta, a cada ano, os desníveis sociais e econômicos.

O investimento do turismo é uma das principais formas de aproveitamento dos recursos naturais para a alavancagem da economia. No que se refere às múltiplas possibilidades de investimentos econômi- cos no setor, as oportunidades são muitas, tanto a curto prazo quanto a longo prazo. Tais investimentos impulsionam o setor de produtos e o setor de serviços como hotéis, bancos, restaurantes, transportes, venda de artesanatos e produtos da terra, a realização de eventos esportivos, festivais de danças, simpósios, congressos, etc.

Um aspecto que torna a economia turística diferente em relação aos outros setores é a sazonalidade, levando a uma oscilação constante, em termos de períodos cujos retornos financeiros dos investimentos são maiores ou menores em épocas diferenciadas. Esses períodos são chamados de alta e baixa estações.

\section{O MERCADO DE INFORMAÇÃO E O SETOR TURÍSTICO}

Com o crescimento do turismo surge atualmente um forte fator restritivo ao desenvolvimento do setor, trata-se dos insuficientes investimentos destinados à informação, publicidade e propaganda, o que tem interferido na decisão dos turistas quanto ao lugar a ser visitado.

As condições específicas de cada estado ou região quanto a oferta de produtos e serviços turísticos, devem ser evidenciadas por meio de serviços de informação ao turista no país e no exterior. O que pressupõe aspectos referentes à cidade em termos de infra-estrutura de lazer, parques de diversões, atrações artísticas e culturais, segurança pública, hospitais, transportes, bancos, restaurantes, serviços de telecomunicações entre outros. De acordo com pesquisa realizada no Estado do Ceará, em 1997, com aproximadamente quinhentos turistas brasileiros e de outros países, observou-se que a falta de informação representa uma das principais dificuldades encontradas antes e durante a viagem, afe- 
tando a qualidade do turismo e a possibilidade de retorno ao Estado.

Como disponibilizar informações de qualidade aos turistas deveria ser uma das principais preocupações de empresas públicas e privadas, agências de viagem, hotéis, restaurantes e bibliotecas para o aumento da vantagem competitiva do mercado.

Nesse perspectiva, com as fortes transformações ocorridas na economia e no setor de serviços como um todo, surge um novo mercado de atuação para o profissional da informação, num momento em que são evidenciados novos "balcões de informação não-convencionais" (MOSTAFA, 1995).

No setor turístico vários são os profissionais que, em parceria, poderão desempenhar importante papel para o crescimento desse mercado, na seleção, tratamento e disseminação da informação. Dentre os quais podemos destacar: técnicos em turismo, administradores, pessoal de marketing, publicidade e propaganda e bibliotecários, para citar apenas alguns.

A questão que se faz necessária é pensar como o bibliotecário somará forças nesse mercado emergente que é o turismo no Brasil, especialmente no Nordeste, em termos de formação profissional, pois os currículos dos cursos de Biblioteconomia brasileiros ainda não contemplam os mercados emergentes de informação e, em sua maioria, a ênfase é dada à formação de profissionais para atuarem nas tradicionais bibliotecas.

Mesmo com as limitações já acentuadas, o desafio maior é a possibilidade de vislumbrar novos caminhos e indícios, principalmente em termos de empregabilidade e ascensão da classe biblioteconômica, le- vando em consideração a dinâmica de um mercado moderno, as exigências de uma sociedade em movimento acelerado e capitalista onde a idéia de poder, riqueza e valor passa necessariamente pelo fator informação, não permitindo, em momento algum, a inércia profissional, independente da área.

Com as políticas de desenvolvimento crescente, vislumbradas no Brasil através do Mercosul, a participação efetiva do bibliotecário no setor turístico visualizando a ampliação do mercado de informação poderá adequar-se pela colaboração profissional em pesquisas de mercado, elaboração de projetos, informativos e guias sobre cultura, lazer, esporte, artesanato, diversão, bares, restaurantes, história e memória da cidade ou região, cidades turísticas, segurança, serviços e ainda na organização de eventos, atendimento a turistas, serviços de informação em aeroportos, agências de viagens e hotéis, serviços de marketing, publicidade e propaganda. Enfim, atividades que estejam direcionadas ao atendimento das necessidades informacionais do turista, profissionais e demais usuários do setor.

\section{VANTAGENS E DESVANTAGENS E OS IMPACTOS DO TURISMO}

Para muitos estudiosos, o turismo representa uma atividade que traz divisas, gera empregos e renda embora traga consigo os efeitos sobre os estilos de vida da comunidade, inflação e a depredação do meio ambiente, bem como o crescimento desordenado.

A maioria dos estudos realizados sobre os impactos do turismo se preocupa somente com os fatores econômicos por serem mais facilmente mensuráveis do que as conseqüências ambientais e 
socioculturais, de caráter mais qualitativos e subjetivos. Para reforçar essa tendência se alinham às questões metodológicas, o interesse do governo e de empresários na geração de riquezas.

A vinda de turistas afeta a vida das pessoas nos municípios. A maneira como os visitantes se comportam, seus costumes e suas relações pessoais com os moradores da região receptora têm um efeito profundo sobre as localidades. Por outro lado, o turista também recebe influências culturais das regiões visitadas contribuindo com uma miscelânea de raças e culturas podendo ter efeitos positivos ou não.

Podemos dimensionar como vantagens do turismo a expectativa de bons empregos e o desejo das comunidades em qualificarem-se profissionalmente para 0 setor, a influência sobre a forma de vida tradicional, ao mesmo tempo que o turismo promove os valores artísticos e comercializa tradições e costumes locais podendo fortalecer e estimular na valorização da cultura e história. A principal vantagem do turismo é o favorecimento do crescimento econômico da região com a possibilidade de melhoria na qualidade de vida da população.

Apesar das várias vantagens trazidas pelo turismo, desvantagens podem ser observadas à medida que todo crescimento pressupõe diferentes formas de adaptação que nem sempre são acompanhadas por todos, como por exemplo: modificações nos padrões de consumo, novos hábitos e costumes, declínio do idioma nativo e transformação de valores, acarretando como desvantagens maiores a prostituição, a delinqüência e o alto custo de vida.

\section{POLÍTICAS DE DESENVOLVI-}

\section{MENTO SUSTENTÁVEL DO TU- RISMO}

O turismo para crescer deve ter qualidade e informação, além de atrativos protegidos, seguros e conservados. Essa qualidade necessita de políticas e diretrizes que garantam o crescimento ordenado das regiões em diferentes aspectos: urbanos, sociais, culturais, econômicos e ambientais.

A criação e implementação de programas e projetos que visem atender às necessidades que o desenvolvimento exige representam os principais veículos de fortalecimento do turismo. Para tanto, é importante a criação de legislações e órgãos fiscalizadores para minimizar os efeitos dos impactos ambientais de áreas a serem exploradas para usos turísticos visando corrigir o crescimento desordenado e colaborando na formação da consciência dos moradores sobre os impactos do turismo.

\section{CONCLUSÕES}

Em diferentes economias no mundo inteiro assiste-se a uma inversão da lógica industrializante como vetor fundamental do desenvolvimento econômico para ascensão do setor de serviços. A geração de emprego desloca-se do setor secundário ao conjunto de atividades do setor terciário. Como um dos principais representantes do crescimento do setor de serviços encontra-se o turismo, notadamente em ascensão, nas últimas décadas, nas regiões brasileiras.

O turismo pode ser evidenciado como um forte aliado ao crescimento econômico e social do País, principalmente na geração de empregos e renda e no desenvolvimento de municípios onde os recursos e as belezas naturais podem ser adequadamente utilizados como formas alternativas de trabalho. 
Além da geração de empregos, o turismo aumenta a arrecadação dos municípios e estados através da cobrança de impostos, como também incentiva o crescimento da economia informal e a criação de micros e pequenas empresas por parte dos moradores.

É importante observar que a oferta de produtos e serviços turísticos deve estar acompanhada de políticas e programas que atendam às necessidades informacionais dos turistas, a qualificação de profissionais para o setor, aproveitamento da mão-deobra local, a criação de legislação e a conscientização da população quanto a esta questão.

Quanto ao mercado de informação, o setor turístico apresenta-se como emergente no sentido de proporcionar a diversos especialistas, inclusive aos bibliotecários, um novo campo profissional, ampliando a concepção de espaço de atuação e a compreensão de que a informação é componente primordial em qualquer lugar onde haja manifestações e experiências humanas.

Essas questões acerca do mercado de informação no setor turístico, ainda iniciais no campo da Biblioteconomia, têm possibilitado repensar as possibilidades de diferentes papéis do bibliotecário numa sociedade global cujas ofertas são muitas e as necessidades de profissionais dinâmicos, qualificados, atualizados e criativos tornamse cada vez mais emergentes. Reconhecer, portanto, esses novos rumos e oportunidades, traduzi-los em políticas concretas de crescimento podem, certamente, contribuir na formação de um novo profissional e na extensão do seu campo de atuação.

\section{REFERÊNCIAS}

BALTASAR, Diamantino Duarte. Turismo: dinâmica social e econômica. São Paulo: Instituto de Cultura e Ensino Padre Manoel da Nóbrega, 1982. 117p.

CASTELLI, Geraldo. Turismo e marketing. Porto Alegre: Sulina, 1984.

EBEL, Roberto et al. Turism and regional growth: empericol study of alternative growth paths for Hawaii. Wheaton: Merton House Publishing, 1981. 243p.

EMBRATUR. Impacto do turismo na economia brasileira. Rio de Janeiro: Embratur, 1991. 53p.

LAGE, Beatriz Helena Gelas; MILONE, Paulo César. Economia do turismo. São Paulo: Papirus, 1991. 122p.

MACHADO, José Geraldo. Turismo: uma indústria abrangente para uma cidade de serviços. Rio de Janeiro: Imprinta, 1987. 92p.

MATHIESON, Alister. Turismo: repercusiones sociales, económicas y físicas. México: Trillas, 1990. 278p.

MELO, Dárdamo Nunes. A importância sócio-econômica do turismo para o Estado do Ceará. Fortaleza: [s.c.p], 1986. 33p.

MOSTAFA, Solange Puntel; PACHECO, Márcia. O mercado emergente de informação. Ciência da Informação, Brasília, v.24, n.2, p.171-180, maio/ago. 1995.

OLIVEIRA, Annibal Uzêda; SECUNDINO, Innal. Turismo: a grande indústria. Rio de Janeiro: Gráfica Barbero, 1985. 221p.

PALOMO, M. S. Economia turística: elementos de una teoria económica del turismo y 
métodos para su análisis quantitativo, tesis doctral. Madri: Innasa, 1979. 100p.

REJOWSKI, Miriam. Turismo e pesquisa científica. Campinas: Papirus, 1996. 167p.

RITCHIE, J. R. Brent. Tourism research. In: PEARCE, Douglas G.; BUTLER, Richard W. Tourism research: critiques and challenges. Londres: Routledge, 1993. P. 201-206.

TEIXEIRA, Maria do Socorro Gondim. Investimentos no turismo do Ceará: uma análise dos impactos sobre produto, renda e emprego. São Paulo: USP, 1996.

WILLIAM, A. M.; SHAW, G. Tourism and economic development. Londres: Pinter Public Shers, 1989. 278p.

\section{Lidia Eugenia Cavalcante}

Professora do Departamento de Comunicação Social e Biblioteconomia da UFC, mestranda em História Social UFRJ/UFC.

\section{Edna Leite Dias}

Graduada em Turismo, Mestranda em Administração, Universidade de Fortaleza UNIFOR.

\section{Title}

The information market in the Brasilian Touristic Sector

\begin{abstract}
Lately, the services sector, especially the tourism area, has represented one of the major factors in the economic growth of the country. Many are the public and private investments on tourism in Brazil, having a strong reflection upon the generation of employment and income. The article emphasizes competitiveness and argues that the quality of touristic products and services rendered have to go through information, one of the main demands the consumers have, even though that market is still neglected. For the professional of information, tourism is an emerging non-conventional market, generating multiple possibilities of actiation.
\end{abstract}

\section{Keywords}

Information and Tourism; Information Market; Professional of Information; Tourism; Economic Growth. 


\section{Titulo}

El mercado de información en el sector turístico brasileño

\section{Resumen}

Señala que el sector de servicios, especialmente el área de Turismo, representa uno de los principales factores de crecimiento económico del País en los últimos años. Muchas son las inversiones públicas y privadas destinadas al Turismo en Brasil, lo que refleja significativamente en la generación de empleo y renta. Destaca que la competitividad y la cualidad de la oferta de productos y servicios turísticos pasan necesariamente por el factor información, evidenciando como una de las principales exigencias de los consumidores de ese mercado, todavía, negligenciado. Para el profesional de la información, el Turismo se presenta como un mercado emergente y no convencional generador de múltiples posibilidades de actuación.

\section{Palabras-Clave}

Información y Turismo; Mercado de Información; Profesional de la Información; Turismo; Crecimiento Económico 